\title{
Solvent Dewaxing of Heavy Crude Oil with Methyl Ethyl Ketone
}

As'ad AM, Yeneneh AM and Obanijesu EO*

Department of Chemical Engineering, Curtin University, Bentley Campus, Perth, W.A. 6102, Australia

\begin{abstract}
Transportation of waxy crude oil along horizontal pipeline usually requires extra energy that costs additional billions of dollars to the industry. This study investigated the feasibility of Methyl Ethyl Ketone (MEK) as a selective solvent to dewax an Australian heavy crude oil and the possible optimum conditions. Experiments were conducted on three solvent to crude oil ratios $(10: 1,15: 1$ and $20: 1)$, three mixing temperatures $\left(40^{\circ} \mathrm{C}, 50^{\circ} \mathrm{C}\right.$, and $\left.60^{\circ} \mathrm{C}\right)$ and three cooling temperatures $\left(-10^{\circ} \mathrm{C},-15^{\circ} \mathrm{C}\right.$ and $\left.-20^{\circ} \mathrm{C}\right)$. Each crude oil sample was weighed out and mixed with MEK at a predetermined mass ratio; the mixture was then heated in a hot water bath and stirred until a thermal equilibrium was achieved. The mixture was then placed in an ethylene glycol bath which had been cooled to the desired temperature using dry ice until the target temperature was achieved. The crystallised wax which forms in the mixture was then vacuum filtered, dried, and weighed. Three samples were prepared for each unique parametric variation, and the average result recorded. The results indicated that MEK dewaxing performance improved at higher mixing temperatures. This could be explained by the disruption of dispersion forces which exist between the molecules in the crude oil, allowing new intermolecular bonds to form between MEK and oil molecules in greater preference than with the wax molecules. It was also discovered that the use of a higher solvent to oil ratio resulted in a greater wax yield that is attributed to a greater oil solubility, considering MEK's greater affinity for oil than wax, as well as a greater number of unbounded MEK molecules for dispersion forces to form when a high solvent to oil ratio is used. In contrast, it was found that a lower cooling temperature resulted in a greater extraction of wax from the mixture. This can be associated with the fact that the decrease in temperature encourages the crystallisation of the wax, as well as providing the system with a preferential condition in which an exothermic process, such as the formation of solute to solvent interactions to take place. Finally, the greatest wax yield $(27.9 \mathrm{wt} \%)$ was achieved at a solvent to oil ratio of $15: 01$, a mixing temperature of $50^{\circ} \mathrm{C}$ and a cooling temperature of $-20^{\circ} \mathrm{C}$. Similar results of approximately $27.6 \mathrm{wt} \%$ wax yield was obtained at a cooling temperature of $-15^{\circ} \mathrm{C}$, which leads us to consider whether the additional energy required to achieve a lower cooling temperature is worth the increased revenue which may be obtained at the marginally greater wax yield when considering a large scale solvent dewaxing application.
\end{abstract}

Keywords: Horizontal pipelines; Methyl ethyl ketone; Solvent dewaxing; Unconventional hydrocarbon; Waxy crude

\section{Introduction}

The global oil demand is expected to increase to about 40 billion barrel of oil (Gbo) per year by 2020 as a result of an increasing population and industrialization [1]. This indicated $60 \%$ increase from the present global demand will assert pressure on the conventional oil supply with current proven global reserves of 1,238 billion barrels. Out of a range of alternative resources, only heavy oils and oil sands which are unconventional hydrocarbon resources are sizable enough to supplement and possibly substitute for the shortage in the conventional oil. Consequently, the increasing difficulty in exploration of the depleting conventional reservoirs leading to more expensive production cost will favour the shift to the unconventional resources [2]. Roughly $75 \%$ of the world's heavy oil reserves can be found in the Orionoco Belt in Venezuela, and in Northern Alberta and Saskatchewan provinces of Canada. Both heavy oils and oil sands have higher viscosity and lower gravity of less than $20^{\otimes}$ API which makes them extremely difficult to produce from subsurface reservoirs and subject the reservoirs to thermal stimulation $[3,4]$. Wax deposition, which is crystallization resulting from phase separation of paraffinic solids from crude oil due to temperature drop also occurs during their transmission in pipelines. Accumulation of these solids could cause severe flow assurance problems that ultimately lead to pipe leakage, rupture and explosion [5,6]. An increased wax deposition is often accompanied by high pigging frequency as curative treatment which costs extra millions of dollars in deferred revenue [7]. Therefore, wax deposition must be properly managed in order to reduce the associated problems as well as increase the heavy oil flowability for an increased market values and ease of processing in refineries.

An effective treatment method for wax deposition as developed by Hamilton and Herman [8] used passive energy to stabilize micelle structures that promote the deposition of paraffin's, asphaltenes and mineral scale particularly in heavy oil pipelines. Solvent dewaxing is another effective treatment method which employs recovery of microcrystalline (or paraffin waxes) from the heavy crude before it is processed [9]. This study investigates the range of optimum performance conditions for solvent dewaxing using methyl ethyl ketone (MEK). MEK is selected for this study due to its rapid evaporation rate, higher solvency, lower viscosity, good miscibility with most hydrocarbons without impact on their characteristic as well as the favourable volume/ mass ratio due to its low density [10,11]. Nimer et al., [12] conducted a similar study by using a mixture of toluene and MEK as carrier solvents; however, pure MEK is used in this study due to its established lower selectivity for paraffinic compounds compared to toluene. Though,

*Corresponding author: Obanijesu EO, Department of Chemical Engineering Curtin University, Bentley Campus, Perth, W.A. 6102, Australia, Tel: +61414512670 E-mail: e.obanijesu@curtin.edu.au

Received February 18, 2015; Accepted March 19, 2015; Published March 26 2015

Citation: As'ad AM, Yeneneh AM, Obanijesu EO (2015) Solvent Dewaxing of Heavy Crude Oil with Methyl Ethyl Ketone. J Pet Environ Biotechnol 6: 213. doi:10.4172/2157-7463.1000213

Copyright: ( 2015 As'ad AM, et al. This is an open-access article distributed under the terms of the Creative Commons Attribution License, which permits unrestricted use, distribution, and reproduction in any medium, provided the original author and source are credited. 
both are good solvents for oil, presence of toluene could negatively impact the solvent dewaxing performance [12]. The effects of changes in solvent to oil ratio, heating temperature and cooling temperature on the amount of wax yielded are studied in this work.

\section{Methodology and Analysis}

\section{Chemicals}

The crude oil with THE composition shown in Table 1 was obtained from Cliff Head oilfield of Roc Oil Pty Ltd, Australia. The MEK, ethylene glycol, and ethanol used for this study were of $100 \%$ purity and supplied by Chem-Supply Pty Ltd, Australia. The pure dry ice used to cool the mixture to desired temperatures was obtained from BOC Limited Pty Ltd. A weighing balance of $\pm 0.5 \mathrm{mg}$ accuracy was used for all weight measurements. The studied crude oil sample was stabilised with $10 \mathrm{ppm}$ hydrogen sulphide and studies were conducted on the mixing and heating, chilling, filtration, and drying stages.

\section{Experimentation}

Heating and mixing: For each unique combination in solvent to oil ratio, heating temperature, and cooling temperature, three identical samples were prepared and the experiments were conducted simultaneously such that an average of the results can be obtained for consistency. To do this, three $150 \mathrm{ml}$ beakers were prepared, into each of which, a 5 g quantity of crude oil sample was added using a $30 \mathrm{ml}$ syringe. Using a $150 \mathrm{ml}$ measuring cylinder, the specified quantity of solvent was weighed out. The first set of experiments used $50 \mathrm{~g}$ of MEK, the second set of experiments used $75 \mathrm{~g}$ of MEK, and the third set of experiments used $100 \mathrm{~g}$ of MEK, corresponding to solvent ratios of 10:1, 15:1, and 20:1 respectively.

A magnetic stirrer was added to each beaker, before it was placed in the hot water bath and covered with a watch glass. The temperature of the water bath was kept constant at $40^{\circ} \mathrm{C}, 50^{\circ} \mathrm{C}$ or $60^{\circ} \mathrm{C}$ using the hotplate which also served to stir the mixture at a constant speed of 180 RPM. An alcohol thermometer with an accuracy of $\pm 0.5^{\circ} \mathrm{C}$ was used to measure the temperature of the mixture. The heating and mixing stage was concluded when the desired heating temperature was achieved in the mixture. This stage is immediately followed by chilling and the beakers are immediately placed in the ethylene glycol cooling bath.

Cooling and filtration of mixture: Following the heating and mixing stage, the mixture was immediately placed in the ethylene glycol and dry ice bath to allow the wax to crystallize. An alcohol thermometer with an accuracy of $\pm 0.5^{\circ} \mathrm{C}$ was used to monitor the temperature of the cooling bath to ensure that the temperature is maintained at $-10^{\circ} \mathrm{C}$, $-15^{\circ} \mathrm{C}$, or $-20^{\circ} \mathrm{C}$. To maintain the cooling temperature, dry ice was added periodically as the temperature of the cooling bath tends to increase as the hot mixture is submerged in the ethylene glycol. An identical alcohol thermometer was also used to monitor the temperature and to stir the mixture to ensure that the wax does not deposit on the walls of the beaker and remains suspended in the liquid mixture. The cooling process was completed after the desired temperature was achieved in the mixture.

Following the cooling stage, the mixture was stirred to ensure that no crystallised wax adhered to the walls of the beaker. The magnetic stirrer was then removed from the mixture using a pair of tweezers and the mixture was vacuum-filtered using $45 \mu \mathrm{m}$ Wathman filter paper. The filter paper containing the wax was then removed and placed on a watch glass in the fume hood for a period of 20 minutes to allow the remaining volatile solvent to evaporate. The filter paper containing the residue was weighed using the weighed. The results were recorded and expressed in yield as a weight fraction of the overall crude oil sample. The filtration procedure was carried out on all three mixtures individually.

Determination of wax yield: The extracted wax was expressed as a percentage yield of the total weight of the original oil sample and calculated using equation 1 :

$$
\mathrm{Y}=\frac{\mathrm{W}_{\mathrm{e}}}{\mathrm{W}_{\mathrm{o}}} \times 100
$$

Where $Y$ is the yield as a percentage of the total weight of the sample; $W_{e}$ is the weight of the extract and $W_{o}$ is the weight of the crude oil sample itself.

The total wax content of the crude oil sample used in this study was $29.9 \%$, or $1.5 \mathrm{~g}$ per $5 \mathrm{~g}$ of crude oil sample. After determining the optimum physical conditions of the solvent extraction process, further analysis of the sample was conducted to determine the overall effectiveness of the process.

\section{Results and Discussion}

\section{Effect of mixing temperature}

Figure 1A shows the wax yield for the varying mixing temperatures. Higher mixing temperature corresponds to a greater yield of wax from the mixture. For a 10:1 solvent ratio, there is a pronounced difference in wax yield between the different mixing temperatures. However, when a higher solvent ratio is used, the yield obtained by the mixtures which were heated to $50^{\circ} \mathrm{C}$ and $60^{\circ} \mathrm{C}$ only differ by up to $0.7 \mathrm{wt} \%$, but marginally outperformed the mixture which was only heated to $40^{\circ} \mathrm{C}$ by up to $1.2 \mathrm{wt} \%$.

Similarly, the cooler chilling temperatures of $-15^{\circ} \mathrm{C}$ and below show a small difference in wax yield of approximately $0.2 \mathrm{wt} \%$ between the mixtures which are heated to $50^{\circ} \mathrm{C}$ and $60^{\circ} \mathrm{C}$, however, the yield is up to $0.7 \mathrm{wt} \%$ more than that which was obtained by the mixture which was only heated to $40^{\circ} \mathrm{C}$ as shown in Figure $1 \mathrm{~B}$.

Figure $1 \mathrm{~B}$ also clearly shows that the dewaxing performance is improved when the mixture is heated to a higher temperature of $50^{\circ} \mathrm{C}$ to $60^{\circ} \mathrm{C}$. This is due to the fact that the higher temperature serves to break apart the dispersion forces between the molecules in the crude oil sample, allowing the MEK to form such forces with free oil molecules in greater preference than that to the paraffinic compounds, resulting in a greater filtration and overall separation performance.

Since the overall wax yields of the mixtures heated to $50^{\circ} \mathrm{C}$ and $60^{\circ} \mathrm{C}$ are only separated by no more than $0.7 \mathrm{wt} \%$, the more economically viable option must be applied if the process was to be applied on a greater scale. It is better to heat the mixture to a temperature no higher than $50^{\circ} \mathrm{C}$ as the additional utility requirements to heat the mixture to $60^{\circ} \mathrm{C}$ is not economically feasible based on the marginal increase in the overall wax yield, as well as the degree of cooling which is required later on in the process. However, it is advisable to conduct a thorough economic analysis and optimization study that accounts for additional

\begin{tabular}{|l|c|c|c|}
\hline Ingredient & Formula & CAS No. & Content \\
\hline Hydrogen Sulphide & $\mathrm{H}_{2} \mathrm{~S}$ & $7783-06-4$ & $<0.005 \%$ \\
\hline Aliphatic Hydrocarbon(s) & $\mathrm{N} / \mathrm{A}$ & $\mathrm{N} / \mathrm{A}$ & $>60 \%$ \\
\hline Aromatic Hydrocarbon(s) & $\mathrm{N} / \mathrm{A}$ & $\mathrm{N} / \mathrm{A}$ & $<1 \%$ \\
\hline
\end{tabular}

Table 1: Properties of the crude oil used for the study 
utility requirements on one hand and the revenue from a slightly higher wax yield on the other hand.

\section{Effect of solvent to oil ratio}

Figure 2 shows that there is a distinct trend between the mixing and chilling temperatures against the overall wax yield. More specifically, it appears that when a high solvent to oil ratio is used, a higher yield is achieved. Similar yield was achieved from the samples which used a 15:1 and 20:1 solvent to oil ratios.

It can be said that although the extraction performance was similar between 15:1 and 20:1 solvent ratios, the maximum wax extraction was achieved at a solvent to oil ratio of 15:1 or greater. The results can be justified by the fact that the high solvent ratio results in a greater reduction of the mixture's viscosity, and the solvent itself enhances the formation and growth of wax crystals, which in turn, resulted in an improved filtration performance. More so, the greater ratio of solvent to oil molecules which have a greater solubility preference for the oil than that of the wax serves to improve the dewaxing performance. This is reflected by the high yield obtained from mixtures with 15:1 and 20:1 solvent ratios.

Although a high performance can be achieved when a high fraction of solvent is used, it is important to consider the implications a high volumetric flow rate of mixture may have on the economics of a large scale process. Compared to the wax yield of mixtures which used a 10:1 solvent to oil ratio, mixtures using a 15:1 ratio were able to achieve up to $2.1 \mathrm{wt} \%$ greater yield. However, no significant performance differences separate the mixtures using a 20:1 and a 15:1 ratio.

Higher volumetric flow rate per unit of wax yield results in a significantly greater pumping power requirement, and a greater duty in the units which serve to recover the solvent. Additionally, a higher raw material cost will be incurred as a result of the greater requirement of solvent. In turn, applying a 20:1 solvent ratio in a commercial scale process may not be economically justifiable, considering the fact that a similar performance can be achieved by using a 15:1 solvent to oil ratio. An economic study which takes into account the additional utilities required for higher volumetric flow rates of mixture can be conducted for further confirmation.

\section{Effect of chilling temperature}

The results presented in Figure 3 shows that a lower chilling temperature results in a greater wax yield, and that the greatest average yield was obtained for solvent to oil ratio of 15:1. Although the wax yield differs by up to $3 \%$ between chilling temperatures of $-10^{\circ} \mathrm{C}$ and $-15^{\circ} \mathrm{C}$, there is no more than $1 \%$ difference in yield when chilling temperatures of $-15^{\circ} \mathrm{C}$ and $-20^{\circ} \mathrm{C}$ are applied to the mixture.

This can be explained by the fact that due to a greater temperature difference, a longer amount of time is required for the mixture to reach thermal equilibrium. This translates to a greater crystallisation time, allowing a greater amount of wax crystals to form [13]. In addition to this, the greater temperature gradient which the mixture is exposed to further encourages the formation of new crystals or nucleation, which enables a greater rate of formation of the wax crystals [13].

Although a greater performance is evident when a chilling temperature of $-20^{\circ} \mathrm{C}$ is applied, the small increase in wax yield may not make it preferable than chilling the mixture to $-15^{\circ} \mathrm{C}$. The optimum chilling temperature can be determined by studying the economic trade-off between a greater cooling duty and a higher wax yield.

\section{Effect of solvent to oil ratio on cake formation}

In the vacuum filtration process, various filter cake characteristics were observed. The appearance of wax crystal clusters varied in size and formation according to the variation in parameters. It was generalised that as the solvent to oil ratio was increased, smaller clusters of wax were formed on the filter paper post filtration. The change in chilling temperature also changed the appearance of the filter cake such that a lower chilling temperature produced larger wax clusters as seen in Figure 4 .

A possible explanation for such various filter cake characteristics is the variance in concentration and cooling residence time. A lower solvent ratio will result in a greater wax concentration, which in turn will result in the formation of large wax crystal clusters. In addition to this, the greater period of cooling for the lower chilling temperatures will result in an increased formation of crystals, which translates to a larger cluster size seen in the filter bed.

\section{Optimum yield point}

At the completion of the experimental study, it was found that the maximum possible wax extraction was obtained when the solvent was mixed with the crude sample at a ratio of $15: 1$, then heated to a temperature of $50^{\circ} \mathrm{C}$ in a hot bath with simultaneous stirring, before immediately chilling it to a temperature of $-20^{\circ} \mathrm{C}$. Three experiments carried out under these conditions produced an average dry wax mass of $1.39 \mathrm{~g}$ from a $5 \mathrm{~g}$ crude oil sample, corresponding to a yield of $27.9 \mathrm{wt} \%$.

\section{Conclusion}

This study has successfully established the effects of parametric variations on wax extraction from an Australian heavy crude oil using

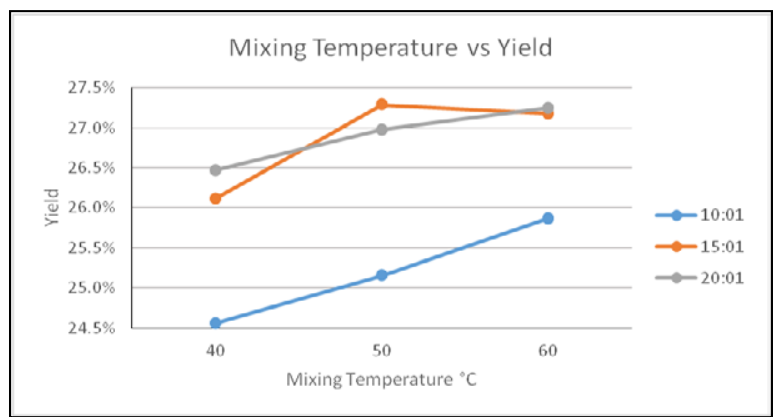

A: Solvent Ratio Comparison

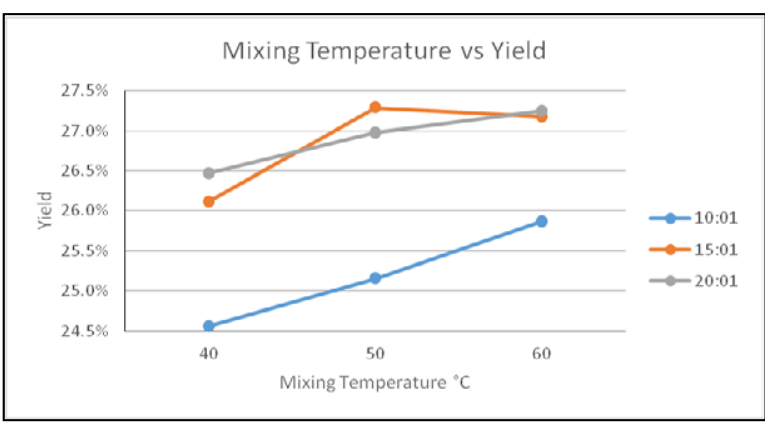

B: Chilling Temperature Comparison

Figure 1: The results of mixing Temperature against Yield 
Citation: As'ad AM, Yeneneh AM, Obanijesu EO (2015) Solvent Dewaxing of Heavy Crude Oil with Methyl Ethyl Ketone. J Pet Environ Biotechnol 6: 213. doi:10.4172/2157-7463.1000213

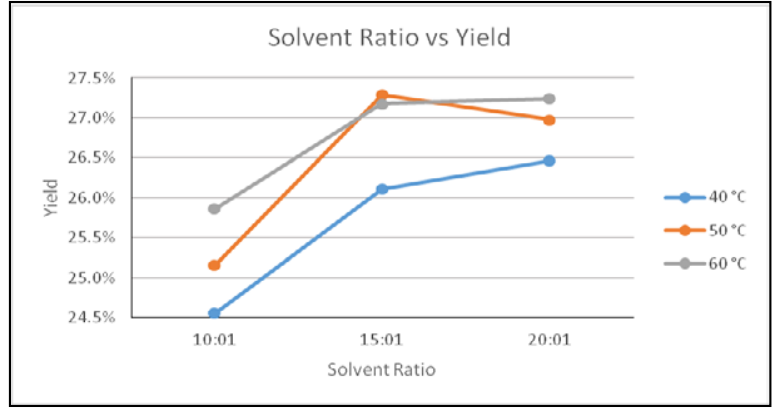

A: Mixing Temperature Comparison

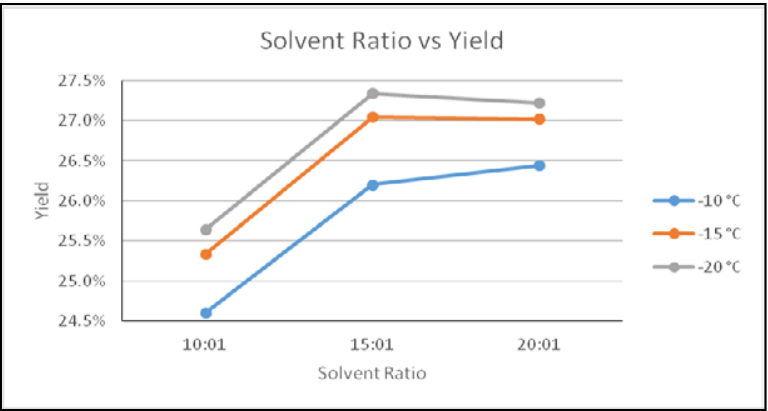

B: Cooling Temperature Comparison

Figure 2: The results of Solvent ratio against Yield.

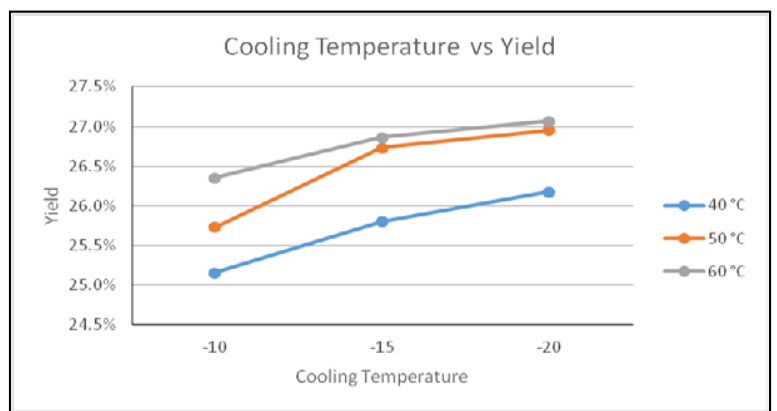

A: Mixing Temperature Comparison

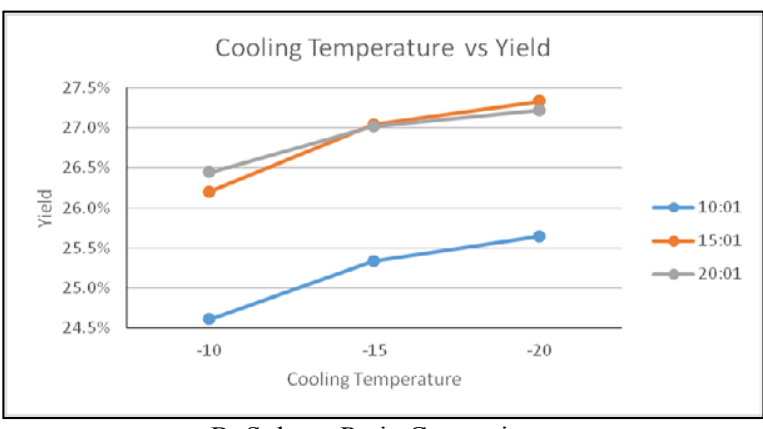

B: Solvent Ratio Comparison

Figure 3: The results of cooling Temperature against Yield.

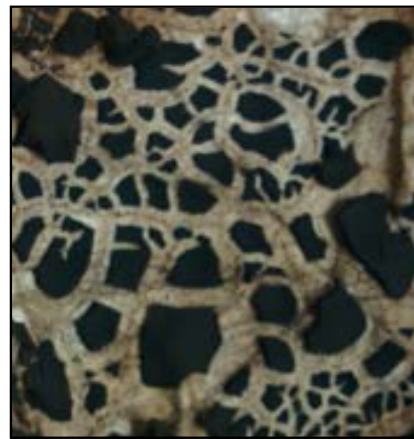

(a) $\quad 20: 1$

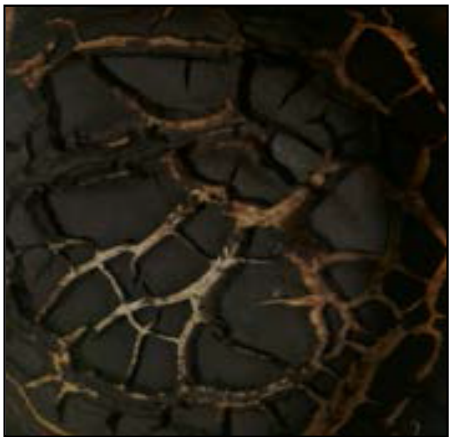

(b) 15 :

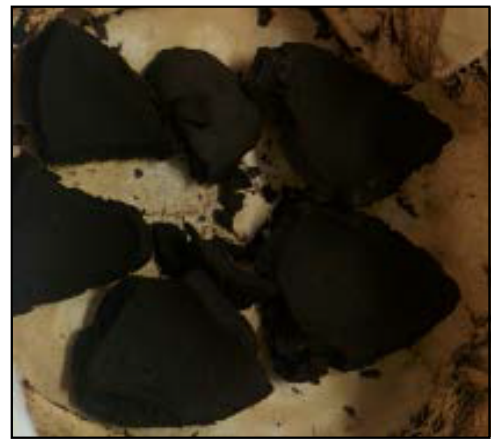

(c)

$10: 1$

Figure 4: Structure and formation of different cake clusters after vacuum filteration.

a pure Methyl Ethyl Ketone solvent. It was observed that the wax yield increases with increasing mixing temperature and solvent to oil ratio, as well as a decrease in chilling temperature. Based on the experimental results it was concluded that the optimum wax yield of $27.9 \mathrm{wt} \%$ was obtained using a 15:1 solvent to crude oil ratio, at a mixing temperature of $50^{\circ} \mathrm{C}$, and a chilling temperature of $-20^{\circ} \mathrm{C}$.

High wax yields of $27.6 \mathrm{wt} \%$ were also observed at a solvent to oil ratio of $15: 1$ under a $50^{\circ} \mathrm{C}$ mixing temperature and a chilling temperature of $-15^{\circ} \mathrm{C}$, as well as at a solvent to oil ratio of $20: 1$, mixed at $50^{\circ} \mathrm{C}$ and chilled at $-20^{\circ} \mathrm{C}$. With no more than $0.3 \mathrm{wt} \%$ yield separating the top three results, which have been obtained under a relatively small margin of operating conditions, more experimental work should be conducted to obtain a better optimum condition for solvent dewaxing over a wider range of operational parameters.
In addition to the experimental optimization, economic optimization and feasibility analysis should be conducted to observe the possibilities for commercial scale implementation. This may include a study on the trade-off between the additional revenue which may be achieved through a higher yield of wax and the additional cost of utilities and raw materials required to achieve such high yields, taking into account other parameters such as processing time, solvent recovery, capital and operating costs which may affect the operation as a whole.

\section{Acknowledgement}

Dr. Emmanuel OBANIJESU wishes to acknowledge ROC Oil Pty, Perth, Australia for providing the waxy crude oil that was used for the study.

\section{References}

1. Campbell CJ, Laherrere JH (1998) The End of Cheap Oil: Global Production 
Citation: As'ad AM, Yeneneh AM, Obanijesu EO (2015) Solvent Dewaxing of Heavy Crude Oil with Methyl Ethyl Ketone. J Pet Environ Biotechnol 6: 213. doi:10.4172/2157-7463.1000213

of Conventional Oil will Begin to Decline Sooner than most People Think, Probably within 10 years, Scientific American.

2. DeSena MFM, Rosa LP, Szklo A (2013), Will Venezuelan Extra-Heavy Oil be a Significant Source of Petroleum in the Next Decades? Energy Policy 61: 51-59.

3. Sahu R, Song BJ, Im JS, Jeon YP, Lee CW (2015) A Review of Recent Advances in Catalytic Hydrocracking of Heavy Residues. Journal of Industrial and Engineering Chemistry, Manuscript In Press.

4. Giacchetta G, Leporini M, Marchetti B (2015) Economic and Environmental Analysis of a Steam Assisted Gravity Drainage (SAGD) Facility for Oil Recovery from Canadian Oil Sands. Applied Energy 142: 1-9.

5. Visintin RFG, Lockhart TP, Lapasin R, D'Antona P (2008) Structure of Waxy Crude Oil Emulsion Gels. Journal of Non-Newtonian Fluid Mechanics 149: 34-39.

6. Liu H, He W, Guo J, Huang Q (2015) Risk Propagation Mechanism: Qingdao Crude Oil Leaking and Explosion Case Study . Engineering Failure Analysis ,Manuscript In Press.

7. Lu Y, Huang Z, Hoffmann R, Amundsen L, Fogler HS (2012) Counterintuitive Effects of the Oil Flow Rate on Wax Deposition. Energy \& Fuels 26: 4091-4097.
8. Hamilton DS, Herman B (2011) The Application of Passive Energy to Production Optimization; Stabilizing the Micelle Structure in Oil to Prevent Deposition of Paraffin, Asphaltenes, and Mineral Scale and Reduce Well-head Viscosity in Heavy Oil. South American Oil and Gas Congress, Maracaibo, Venezuela, October 18.

9. Speight JG (2006) The Chemistry and Technology of Petroleum. (5thedn) CRC Press, Boca Raton, Florida

10. Beringer LT, Xu X, Wan SW, Shih W, Habas R, et al. (2015) An Electrospun PVDF-TrFe Fiber Sensor Platform for Biological Applications. Sensors and Actuators A: Physical 222: 293-300.

11. Hu G, Li J, Hou H (2015) A Combination of Solvent Extraction and Freeze Thaw for Oil Recovery from Petroleum Refinery Wastewater Treatment Pond Sludge Journal of Hazardous Materials 283: 832-840.

12. Nimer AA, Mohamed AA, Rabah AA (2010) Nile Blend Crude Oil: Wax Separation Using Mek Toluene Mixtures. Arabian Journal for Science and Engineering 35: 17-24.

13. Correra S, Fasano A, Fusi L, Primicerio M, Rosso F (2007) Wax Diffusivity under given Thermal Gradient: A Mathematical Model. Journal of Applied Mathematics and Mechanics 87: 24-36. 